\title{
ANÁLISE E SIMULAÇÃO DA GESTÃO DA PRODUÇÃO DE EMPRESA: UMA ABORDAGEM DE DINÂMICA DE SISTEMAS
}

\section{ANALYSIS AND SIMULATION OF THE MANAGEMENT OF COMPANY PRODUCTION: A SYSTEMS DYNAMICS APPROACH}

\author{
Bruno Oliveira Nascimento*E-mail: bruno.nascimento@ymail.com \\ Gisele Tessari Santos, ${ }^{\star * *}$ E-mail: giseletessari@yahoo.com.br \\ *Instituto de Educação Tecnológica (IETEC), Belo Horizonte, MG \\ ** Instituto Brasileiro de Mercado de Capitais (IBMEC), Belo Horizonte, MG
}

\begin{abstract}
Resumo: No âmbito da gestão da produção, devido à sua complexidade e dinamicidade, os gestores e demais tomadores de decisão devem planejar a produção e analisar o processo produtivo de forma efetiva e minuciosa. A fim de auxiliar no processo de tomada de decisão, existem diversas técnicas de modelagem e simulação de processos. Neste trabalho, o objetivo foi modelar e simular a gestão da produção em uma empresa que fabrica produtos ligados à comunicação visual com foco em produção para estoque, por meio da técnica de dinâmica de sistemas. Inicialmente, o modelo foi validado utilizando-se dados históricos e, posteriormente, simularam-se o cenário base e mais três cenários a fim de verificar o comportamento do sistema diante da redução do estoque desejado e do aumento da previsão de vendas. Concluiu-se que a análise e simulação da gestão da produção da empresa por meio da técnica de dinâmica de sistemas é viável e relevante para auxiliar os gestores na definição dos planos de vendas, estoque e produção e na identificação do impacto dos gargalos produtivos no sistema. Concluiu-se, ainda, que a atual capacidade produtiva da empresa analisada atende de forma satisfatória sua atual demanda.
\end{abstract}

Palavras-chave: Modelagem e Simulação Dinâmica; Gestão Integrada da Produção; Fabricação para Estoque. Análise de Cenário.

Abstract: Regarding production management, due to its complexity and dynamicity, decision-makers should plan and analyze the production process effectively and thoroughly. To assist in the decisionmaking process, there are several process modeling and simulation techniques. In this work, the objective was to model and simulate production management in a company that manufactures visual communication products with a focus on production to stock through the system dynamics technique. Initially, the model was validated, and later, the base scenario and three scenarios were simulated to verify the system behavior against the desired inventory reduction and the sales forecast increase. In conclusion, the company production management analysis and simulation through the system dynamics are feasible and relevant to assist managers in the definition of sales, inventory and production plans, and the identification of the impact of productive bottlenecks in the system. Also, the analyzed company's current productive capacity satisfies its current demand.

Keywords: Dynamic Modeling and Simulation. Integrated Production Management. Make-to-stock. Scenario Analysis. 


\section{INTRODUÇÃO}

No âmbito da gestão da produção, devido à sua complexidade e dinamicidade, os gestores e demais tomadores de decisão devem planejar a produção e analisar o processo produtivo de forma efetiva e minuciosa. Planejar a produção é uma atividade complexa e exige participação efetiva de todos os responsáveis pelos processos. Para isso, deve existir sinergia entre as mais diversas áreas de uma organização, como marketing, vendas, produção e compras (GODINHO FILHO, 2009).

A fim de auxiliar no processo de tomada de decisão, existem diversas técnicas de modelagem e simulação de processos. De maior relevância para este trabalho, destaca-se a técnica de simulação de Dinâmica de Sistemas (DS). Originalmente, proposta por Jay Forrester (1968), a DS auxilia em uma melhor compreensão das interações entre os processos dos sistemas dos mais diversos setores, como educação, pesquisa, negócios, meio ambiente e social, permitindo a simulação de diferentes cenários e, consequentemente, ampliando a compreensão do comportamento do sistema como um todo (FORRESTER, 1968).

Domingos et al. (2015) desenvolveram um modelo de DS que possibilitou uma visão sistêmica do processo de Planejamento de Vendas e Operações (S\&OP Sales and Operations Planning), integração com a área financeira, além de permitir, por meio de sua simulação, a geração de múltiplos cenários, análise estatística ao considerar variáveis probabilísticas no modelo e aprendizado organizacional. Outra vantagem do modelo desenvolvido pelos autores é a agilidade na execução de diferentes planos de $S \& O P$ e na tomada de decisão já que o tempo de execução da simulação é de segundos.

Devido às vantagens da técnica de DS e do complexo modelo desenvolvido por Domingos et al. (2015), tomar-se-á parte deste modelo como base do presente trabalho. A técnica de simulação e modelo utilizados justificam-se por proporcionar aos gestores uma visão holística do sistema de produção e seu funcionamento e por permitir gerar, de maneira eficaz, diferentes cenários contribuindo, assim, para a previsão de diversas situações futuras o que possibilita a empresa analisar o ambiente previamente e se preparar criando planos de ações e estratégias para os cenários mais prováveis. Dessa maneira, tem-se uma gestão mais eficiente da 
produção da empresa analisada. Cabe ressaltar ainda que Domingos et al. (2015) não aplicaram o modelo desenvolvido em uma empresa utilizando dados reais. Os autores utilizaram dados hipotéticos. Neste trabalho, validou-se parte do modelo proposto pelos autores utilizando-se dados reais de uma empresa que fabrica produtos de comunicação visual sob encomenda (Make to order - MTO) e padronizados (Make to stock - MTS). Apenas o sistema produtivo MTS foi objeto de estudo. Por definição da diretoria da empresa analisada, a fabricação de produtos ligados à comunicação visual deve envolver baixos níveis de estoque, ou estoque zero (para alguns materiais). Portanto, os gestores devem controlar de maneira mais eficiente o lead time (tempo de entrega) dos insumos e matérias-primas envolvidas na fabricação destes produtos. Cabe ressaltar que altos lead times impactam diretamente na imagem da empresa e na satisfação dos clientes. Estes impactos foram constatados pela empresa por meio do registro de e-mails enviados pelos clientes ao setor comercial reclamando sobre atrasos nas entregas dos produtos.

Diante do exposto, o objetivo deste trabalho é modelar e simular o sistema de produção de uma empresa brasileira de pequeno porte do setor gráfico, por meio de dinâmica de sistemas, tendo por finalidade avaliar o desempenho atual da empresa e melhor compreender os fatores que afetam diretamente o seu desempenho produtivo. $O$ modelo e técnica de simulação proposta foram validados utilizando dados históricos da empresa e comparando-os com os resultados obtidos por meio das simulações. Diferentes cenários foram analisados a partir dos principais indicadores de desempenho da produção.

\section{REFERENCIAL TEÓRICO}

\subsection{Gestão da produção integrada aos processos de compras e vendas}

De acordo com Souza (2014), a produção, a compra e a venda são vistos como processos de negócios-chave dentro do ambiente empresarial, independentemente da estrutura organizacional. Pedroso (2015) complementa que as empresas precisam se preocupar em construir maior sincronia entre demanda e suprimentos, buscando equilíbrio entre volume e mix de produtos. Esta sincronia, 
por sua vez, reflete positivamente nas vendas e nas entregas de produtos e serviços, levando a uma cadeia de suprimentos mais alinhada.

Dessa maneira, o balanceamento adequado entre demanda e suprimentos contribui para o aumento do nível de serviço oferecido aos clientes. Para este balanceamento, deve-se planejar a demanda, os materiais e a capacidade, levandose em consideração as previsões, as restrições de materiais e capacidade, e as recomendações dos gerentes (TOMAS et al., 2012).

O processo integrado de produção, vendas e compras, conhecido como processo de S\&OP tem sido amplamente estudado por diversos autores em diversas áreas. Kralik (2016) propôs uma metodologia para implementação do processo de S\&OP contemplando o mapeamento do processo e a sequência de atividades necessárias, além de demonstrá-la através da sua aplicação numa empresa automotiva, o que resultou na padronização dos processos de gestão de informação, demanda e produção da empresa analisada, permitindo adaptações em empresas de diferentes segmentos. Baseando-se nas práticas de S\&OP, Zattar (2016) desenvolveu, junto a representantes das áreas de Marketing, Vendas e Engenharia de uma empresa de grande porte do setor de serviços de telecomunicações, uma ferramenta de análise que unifica dados técnicos e mercadológicos a fim de melhorar a visibilidade de informações entre as áreas e possibilitar o alinhamento de ações e de estratégias da empresa pesquisada. Leite et al. (2017) realizaram o levantamento dos principais desafios e oportunidades do planejamento S\&OP, por meio de um estudo de caso em uma empresa do Sul de Minas Gerais. Verificou-se que o planejamento estratégico, que alinha as necessidades de estoque com as demandas dos clientes, gera vantagem competitiva à empresa analisada devido à redução do custo de armazenamento e transporte de materiais, possibilitando a redução do preço final de seus produtos, garantindo, assim, a satisfação dos clientes e aumentando sua participação de mercado e sua competitividade.

\subsection{Dinâmica de sistemas aplicada à gestão da produção e suprimentos}

A DS é uma metodologia que utiliza conceitos de simulação dinâmica não linear permitindo modelar e simular, portanto, modelos complexos e dinâmicos. 
Originalmente, a metodologia foi utilizada no ambiente industrial e tomou como base conceitos oriundos da teoria de controle. Posteriormente, foram identificadas aplicações de DS em outras áreas como planejamento militar, negócios, políticas públicas, biologia, física e ciências sociais (FORRESTER, 1968; STERMAN, 2000).

Os trabalhos de Jay W. Forrester, a partir da década de 50, e seu livro Industrial Dynamics, lançado em 1968, originaram inúmeros debates no meio acadêmico sobre a viabilidade da dinâmica industrial se transformar em uma teoria geral de análise de sistemas. Publicações como a do Senge (1994) e do Richmond (1993) integraram os principais trabalhos no campo de DS (MORAIS, 2004).

Especificamente na área da gestão da produção e suprimentos surgiram diversos estudos. De Medeiros Júnior et al. (2009) analisaram a contribuição da DS para a gestão de recursos tangíveis e intangíveis de uma organização, seus interrelacionamentos e padrões de comportamento ao longo do tempo, considerando ferramentas quantitativas de simulação para a construção de modelos. Nesta análise, foi ressaltada a necessidade para se compreender como, por que e onde 0 desempenho organizacional tem se desenvolvido ao longo do tempo e que consequências podem ocorrer no futuro se determinadas decisões forem tomadas. O objetivo era gerar aprendizado.

Suryani et al. (2010) desenvolveram um modelo de DS para prever a demanda futura de cimento na Indonésia e verificar a necessidade de expansão de capacidade de acordo com projeções de demanda. De acordo com os autores, seu trabalho pode ser considerado um estudo piloto e existem várias áreas que ainda necessitam de mais pesquisas. Duas áreas destacadas pelos autores são a área de estratégia de manufatura, que estabelece uma relação entre S\&OP e planejamento de longo prazo em um sistema de planejamento e controle da produção, e a área de gestão de desempenho e receita, quando as empresas precisam expandir sua capacidade a fim de atender a uma demanda crescente.

Domingos et al. (2015) desenvolveram um modelo de DS com objetivo de analisar as interações existentes nos processos típicos do ciclo $S \& O P$, bem como as interações com os demais processos que estão implicitamente envolvidos nas decisões resultantes do $S \& O P$. Para isso, os autores construíram um diagrama de enlace causal mostrando as relações de causa e efeito nas diversas áreas 
funcionais de uma empresa, representando, assim, todo o processo S\&OP. Este diagrama foi, então, transformado em um diagrama de fluxo que representa de maneira mais detalhada o relacionamento entre sete macroprocessos: suprimentos, produção, capacidade, previsão de vendas, custeio por absorção, faturamento/análise econômica e fluxo de caixa. Após, os autores definiram um projeto de experimento a partir de uma base de dados hipotética e simularam diferentes cenários. Neste trabalho, foi utilizado parte do modelo proposto pelos autores.

\section{METODOLOGIA}

A primeira etapa desta pesquisa consistiu no desenvolvimento do diagrama causal considerando o modelo proposto por Domingos et al. (2015) simplificado para entender as regras de negócio bem como os feedbacks de reforço e equilíbrio do sistema. Com base neste diagrama, desenvolveu-se o modelo de fluxo de DS para o processo de produção da empresa pesquisada, que permite um maior detalhamento da relação entre as variáveis do processo e sua implementação computacional em softwares de DS. O modelo DS foi, então, implementado usando dados reais dos produtos padronizados (MTS) da empresa e foi simulado para diferentes cenários. A análise dos cenários foi realizada com base na comparação de diferentes indicadores de desempenho para identificar os fatores que afetam o desempenho da empresa em estudo.

\subsection{Modelo de dinâmica de sistemas para gestão da produção}

Na Figura 1, observa-se o diagrama causal do sistema de produção integrado à compras e vendas desenvolvido com base no modelo de Domingos et al. (2015). As variáveis foram subdivididas em quatro macroprocessos: previsão de vendas, produção, suprimentos e capacidade. As variáveis com nome em letra maiúscula são as variáveis exógenas do modelo.

No diagrama apresentado na Figura 1, cada seta representa um relacionamento de causa e efeito entre duas variáveis. Dessa maneira, as relações 
positivas implicam que as variáveis crescem ou decrescem na mesma direção. Por exemplo, quanto menor a "produção", menor o "estoque de produtos acabados". Por outro lado, as relações negativas implicam que as variáveis crescem ou decrescem de maneira inversa. Neste caso, quanto menor o "estoque de matéria-prima", maior a "lista de compras" de matéria-prima.

Figura 1 - Diagrama causal do sistema de gestão da produção simulado

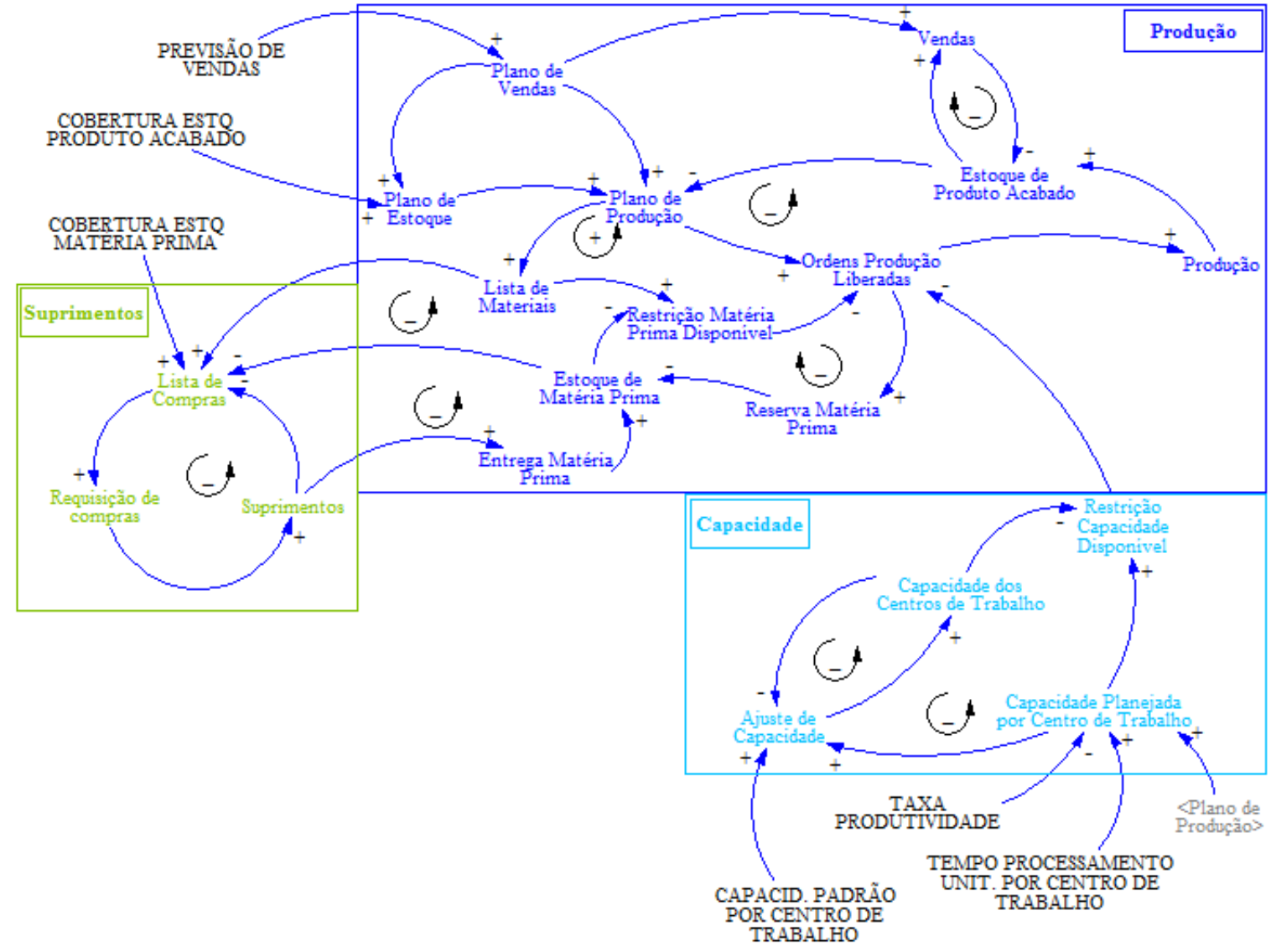

Fonte: Adaptado de Domingos et al. (2015).

No diagrama da Figura 1 existe basicamente dois tipos de feedback (ciclos de retroalimentação): positivo (loop de reforço) e negativo (loop de balanço). Em um loop de reforço o status do sistema continuará crescendo ou decrescendo com o tempo. Já em um loop de balanço o sistema tende a estabilizar (HSIEH, 2018).

Por meio do diagrama causal, também é possível, de maneira mais estratégica, entender as relações entre os macroprocessos. Assim, um aumento no plano de vendas (macroprocesso de previsão de vendas) provoca um aumento no plano de produção (macroprocesso de produção) e na aquisição de suprimentos 
(macroprocesso de suprimentos) - relação positiva. Por outro lado, este aumento no plano de produção (macroprocesso de produção) provoca um aumento na capacidade planejada por centro de trabalho (macroprocesso de capacidade) relação positiva - que pode limitar a produção de acordo com o aumento da restrição da capacidade disponível nos centros de trabalho - relação negativa.

O modelo conceitual apresentado na Figura 1 foi convertido em um modelo de estoque e fluxo permitindo, assim, maior detalhamento da relação entre as variáveis do processo. A seguir, apresentam-se os quatro macroprocessos que compõem o sistema de produção analisado e são descritas as principais relações entre as variáveis. As definições de cada variável utilizada no modelo e as equações detalhadas podem ser encontradas em Domingos et al. (2015).

O modelo de DS para os macroprocessos "Previsão de Vendas", "Produção" e "Suprimentos" pode ser observado na Figura 2. O processo de simulação inicia-se a partir da atualização de todas as variáveis do tipo estoque do modelo e com a entrada de dados referente à previsão de vendas de cada família de produto acabado considerada no modelo. A variável de entrada de previsão de vendas é exógena, uma vez que o modelo não tem a intenção de realizar métodos de previsão e é representada pelo valor médio de uma distribuição probabilística definida pelo gestor na variável auxiliar "Plano de Vendas". Também foi utilizado um método de suavização exponencial simples, conectando a variável de estoque "Demanda" e a variável de fluxo "EntradaPrev" com o objetivo de gerar o plano de estoque inicial (Figura 2).

A fim de se estabelecer um plano inicial de estoque é necessário definir as taxas de cobertura de estoque, de acordo com o cálculo da demanda média prevista - variável "Demanda". Adicionalmente, deve-se definir o estoque desejado ("Estq_Desejado") como uma variável de entrada do plano de estoque.

Pode-se observar, na Figura 2, a estrutura de DS para os macroprocessos "Produção" e "Suprimentos". Os dados de entrada do macroprocesso "Produção" é a previsão de vendas e o plano de estoque, que são fornecidos pelo macroprocesso "Previsão de Vendas", descrito anteriormente. Assim, os planos iniciais de vendas e de estoque, definidos para o processo, são submetidos às restrições de recursos. 
O plano de produção é definido no sistema em função da diferença entre os níveis de estoque de cada família de produto acabado e as necessidades planejadas para vendas e estoque de cada mês no horizonte de planejamento previamente definido. Verifica-se, também, no macroprocesso "Produção" a necessidade da lista de materiais para as famílias de produto acabado, de acordo com os volumes de produção definidos no plano de produção. Com base nesta lista, calcula-se a quantidade de matéria-prima necessária a fim de atender o plano de produção. Este volume de matéria-prima calculado é, então, transferido ao macroprocesso "Suprimentos" no qual se verifica as restrições de matéria-prima para definição do volume a comprar. Neste trabalho, diferentemente do modelo de Domingos et al. (2015), no macroprocesso "Suprimentos", não foi considerado o fluxo de caixa, já que o foco é apenas o sistema produtivo e sua capacidade.

Figura 2 - Modelo de DS para os macroprocessos "Previsão de Vendas", "Produção" e "Suprimentos"

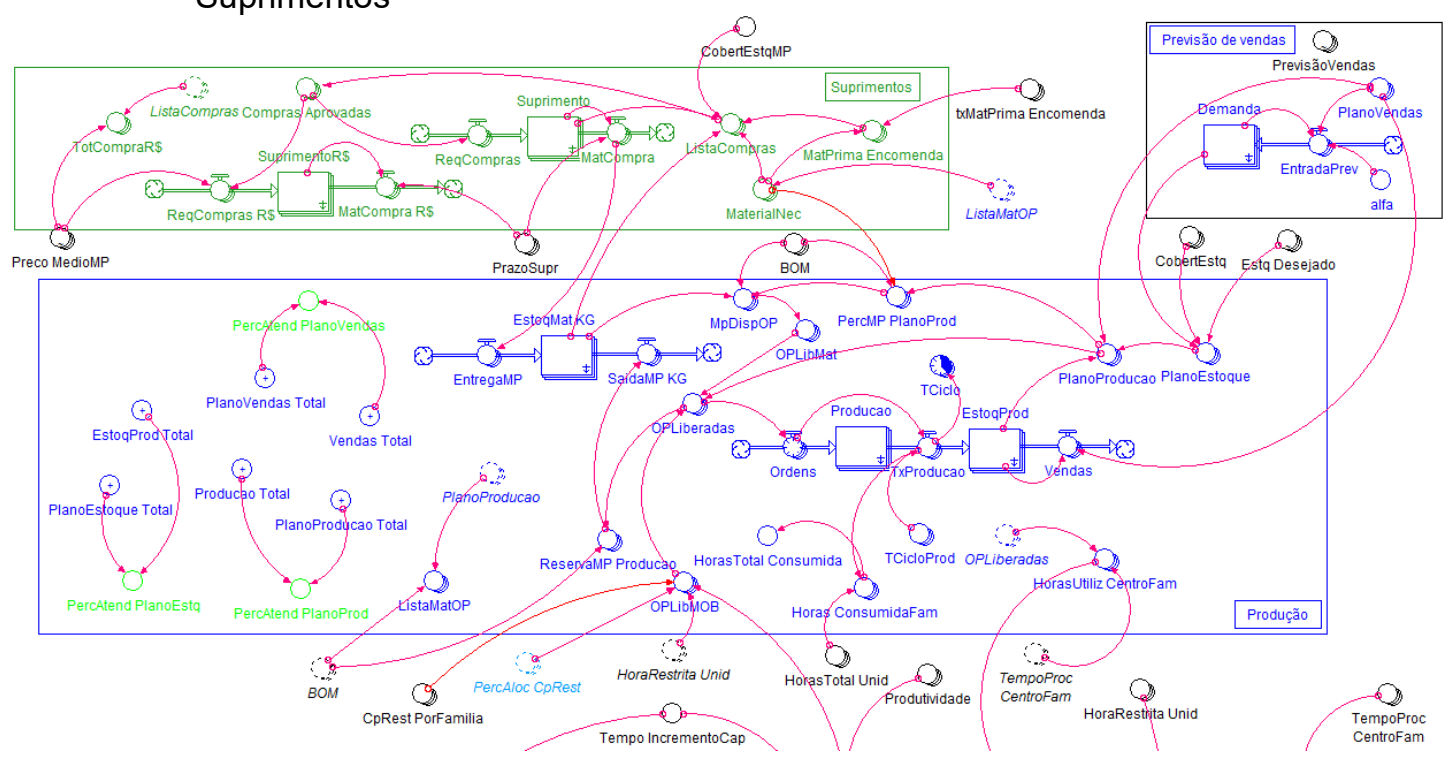

Fonte: Domingos et al. (2015)

Depois da verificação dos níveis de estoque de matéria-prima, define-se o volume de produção possível durante o período de planejamento. Em seguida, definem-se os volumes das ordens de produção que serão liberadas para entrada na produção, efetivando a transferência da matéria-prima para o Work in Process (WIP) de produção. O WIP deve considerar as horas utilizadas de mão de obra e a matéria-prima necessária. As ordens em processo de produção só serão concluídas 
após os tempos de ciclo de produção. Os tempos de ciclo de produção, por variarem e, portanto, por possuírem grau de incerteza, são definidos por uma distribuição de probabilidade para cada família de produto acabado. Após a conclusão do processo de produção, ocorre a baixa dos estoques em processamento (WIP) e o produto acabado passa a ser considerado no estoque de produtos acabados, ficando disponível para vendas.

O dado de entrada no macroprocesso "Suprimentos" é a lista de famílias de matéria-prima necessária para atender ao plano de produção das famílias de produto acabado fornecida pelo macroprocesso "Produção". A partir dessa lista, inicia-se o cálculo da necessidade de compra de matéria-prima.

Definidas as quantidades a comprar, estas são compostas pelo preço unitário de compra, que é definido para cada família de matéria-prima em cada mês do período de planejamento, formando-se assim o plano de suprimentos. Após a definição do plano, serão confirmadas as requisições de compras e transferidas para carteira de compras em que permanecerão até o prazo de suprimento estabelecido para a família de matéria-prima, quando, então, ocorrem as entradas no estoque em valores de custos e quantidades.

Por sua vez, no macroprocesso "Capacidade", o dado de entrada é o plano de produção, que define o volume de produção para cada família de produto acabado. Este macroprocesso inicia-se a partir do cálculo do total de horas trabalhadas, que estão relacionadas ao centro de trabalho restrito, definido para cada família de produto acabado. Vale ressaltar que o centro de trabalho restrito é aquele que limita o desempenho ou a capacidade do sistema. Adicionalmente, considera-se a taxa de produtividade definida para cada centro de trabalho, além do tempo padrão necessário para a produção de uma unidade de cada família de produto. Assim, consegue-se obter o total de horas de capacidade planejada do centro restrito, bem como o percentual de alocação da capacidade restrita para cada família de produto.

Em seguida, comparam-se as horas planejadas às horas de capacidade padrão definida para o centro restrito. A diferença entre estas horas resulta na definição do volume de horas necessárias para se ajustar a capacidade atual à capacidade planejada. O macroprocesso "Capacidade" é mostrado na Figura 3. 


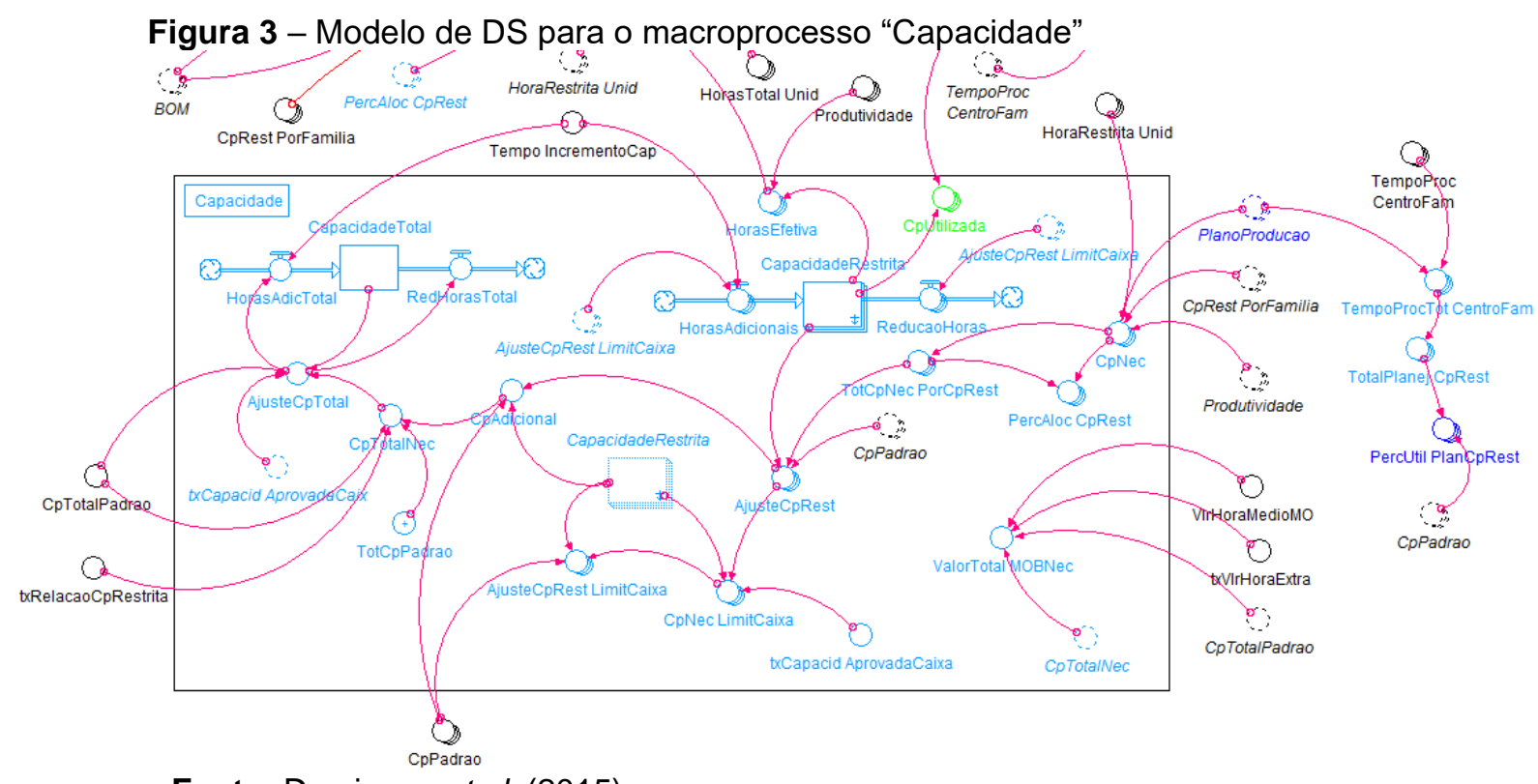

Fonte: Domingos et al. (2015)

No macroprocesso "Capacidade" são consideradas as restrições necessárias para a realização de ajustes de horas de capacidade. Esta estratégia para atendimento ao plano de produção envolve o custo adicional de horas extras e o tempo de atraso para a realização dos ajustes. Neste trabalho, no macroprocesso "Capacidade", não foram considerados o caixa financeiro e seu limite para análise da capacidade produtiva. Assim, o custo de horas extras foi calculado no modelo apenas para consultas por parte dos gestores a fim de norteá-los na tomada de decisão.

\subsection{Dados da Simulação e Cenários}

Assim como proposto por Domingos et al. (2015), as seguintes variáveis foram consideradas estocásticas e, portanto, descritas por meio de funções de distribuição de probabilidade adequadas para o caso estudado: prazo médio de entrega de suprimento, tempo de ciclo de produção e previsão de vendas.

Devido à variabilidade das variáveis estocásticas, para aumentar a confiabilidade dos resultados, foram realizadas 10 replicações para cada cenário. Em seguida, para se calcular os indicadores de desempenho do sistema de produção, calcularam-se a média dos valores desses indicadores obtidos nas 10 replicações. 
O modelo e técnica de simulação foram validados utilizando os dados históricos dos seis primeiros meses do ano de 2017 coletados na empresa analisada e comparando-os com os resultados obtidos por meio das simulações. Cabe destacar que a simulação do cenário base envolveu todos os meses do ano de 2017, considerando-se que, para os meses de julho a dezembro de 2017, calcularam-se as previsões de vendas da empresa por meio da simulação do modelo tomando como base os dados reais do mês de junho. Foram considerados no modelo cinco centros de trabalho, dez famílias de matérias primas e cinco famílias de produtos acabados. Todos os dados de entrada do modelo simulado em relação à empresa pesquisada estão disponíveis em Nascimento (2017).

A fim de identificar os fatores críticos que afetam o desempenho e competitividade da empresa analisada, diferentes cenários foram simulados e analisados. Estes cenários consideraram o efeito de duas variáveis relevantes para o processo de produção: previsão de vendas e estoque desejado de produto acabado. As variáveis selecionadas são consideradas estratégicas para o processo de gestão da produção pela diretoria da empresa estudada, em função dos impactos que essas variáveis podem gerar no sistema de produção como um todo.

Para a construção do cenário 1, o estoque desejado foi reduzido em $50 \% \mathrm{em}$ todos os meses em relação ao estoque desejado do cenário base, mantendo-se as demais variáveis inalteradas. Já para a construção do cenário 2, a previsão de vendas foi aumentada em $4 \%$ ao ano $(0,33 \%$ ao mês) em relação ao valor do cenário base, mantendo-se inalterados os demais dados de simulação. Cabe destacar que o aumento na previsão de vendas se deu em função da perspectiva de crescimento do mercado gráfico e de comunicação visual, oriunda de levantamentos da Associação Brasileira da Indústria Gráfica (ABIGRAF), que previu um crescimento do setor em $4 \%$ ao ano (ABIGRAF, 2016). Por fim, para a construção do cenário 3 , foram consideradas, de maneira simultânea, as duas alterações descritas anteriormente nos cenários 1 e 2. As demais variáveis do cenário base permaneceram inalteradas.

Calcularam-se os seguintes indicadores de desempenho no período desejado: percentual de atendimento ao plano de vendas, percentual de utilização da capacidade do centro de trabalho restrito e volume de produção. 


\section{RESULTADOS E DISCUSSÃO}

O modelo simplificado foi implementado e simulado por meio do software iThink $\circledast$. O método de integração escolhido para a simulação foi o método de Euler, por ser o único método dentre os disponíveis no software utilizado que permite o uso do Cycle-Time - modo de implementação do modelo desenvolvido. O passo de tempo (dt) utilizado foi de 0,25 mês. Este foi o passo de tempo que melhor representou o sistema simulado durante o período analisado.

\subsection{Validação do modelo}

Para validar o modelo, primeiro coletaram-se dados históricos no período de janeiro a junho de 2017. A fim de verificar quão eficaz o modelo utilizado é para predizer o comportamento do sistema real, utilizou-se o erro relativo percentual (ERP) como medida de erro. O ERP referente aos principais indicadores de desempenho calculados pode ser visto na Tabela 1.

Tabela 1 - Erro relativo percentual referente aos indicadores de desempenho
\begin{tabular}{cc} 
no período simulado de acordo com os dados de validação \\
\hline Indicadores & ERP (\%) \\
\hline Vendas Totais & 5,30 \\
Produção Total & 1,96 \\
\% Atend. ao plano de vendas & 4,38 \\
$\%$ Utiliz. capacidade restrita & 3,10 \\
\hline
\end{tabular}

Fonte: Do autor (2017).

Diante dos resultados apresentados na Tabela 1, constata-se que o modelo proposto é válido para predizer o comportamento do sistema produtivo real da empresa, uma vez que o maior ERP encontrado em relação aos indicadores de desempenho calculados para o período simulado foi de $5,30 \%$.

\subsection{Análise dos resultados de simulação do cenário base}

Para simulação do cenário base, salienta-se que, para os meses de janeiro a junho de 2017 , foram utilizados os dados reais referentes às vendas da empresa 
estudada. Já para os meses de julho a dezembro de 2017, calcularam-se as previsões de vendas da empresa por meio da simulação do modelo tomando como base os dados reais do mês de junho. Observa-se na Figura 4 o plano de vendas e as vendas por família de produtos acabados simulados para o ano de 2017.

Após a simulação, constatou-se que o indicador "Percentual de Atendimento ao Plano de Vendas" total atingiu o valor médio de 98,31\% ao mês. Esse percentual indica que as vendas totais simuladas no período atenderam, de forma condizente, ao plano de vendas predito.

A produção total foi equivalente a 47.563 unidades produzidas no ano de 2017, de acordo com a simulação. Verificou-se que, para uma demanda média de 4.347 unidades/mês, considerando as cinco famílias de produtos acabados, a média mensal de produção foi equivalente a 4.231 unidades, à exceção do primeiro mês de 2017, cuja média de produção foi de, apenas, 1.021 unidades.

Conforme nota-se na Figura 5, o baixo volume de produção observado no mês de janeiro ocorreu devido a um nível de estoque mais elevado de produtos acabados neste mês, tornando-se desnecessário um alto volume de produção.

Constata-se também na Figura 5 que, nos dois primeiros meses do ano de 2017, o modelo simulado apresentou um maior nível de estoque de produtos, em comparação aos demais meses do mesmo ano. Consequentemente, a produção mensal foi, proporcionalmente, menor nestes meses que nos demais meses de 2017, uma vez que o grande acúmulo de estoque presente no início do processo, juntamente com o volume mensal de produção, resultou em um atendimento satisfatório à demanda. A partir do mês de abril de 2017, os níveis de estoque e produção se mantiveram, consideravelmente, estáveis comprovando que o ciclo de retroalimentação (feedback) de equilíbrio considerado nesta parte do modelo simulado predominou em relação ao ciclo de reforço. Além disso, foi possível observar que a demanda se manteve estável durante todo o período analisado. 
Figura 4 - Comparativo do plano de vendas e das vendas por família de

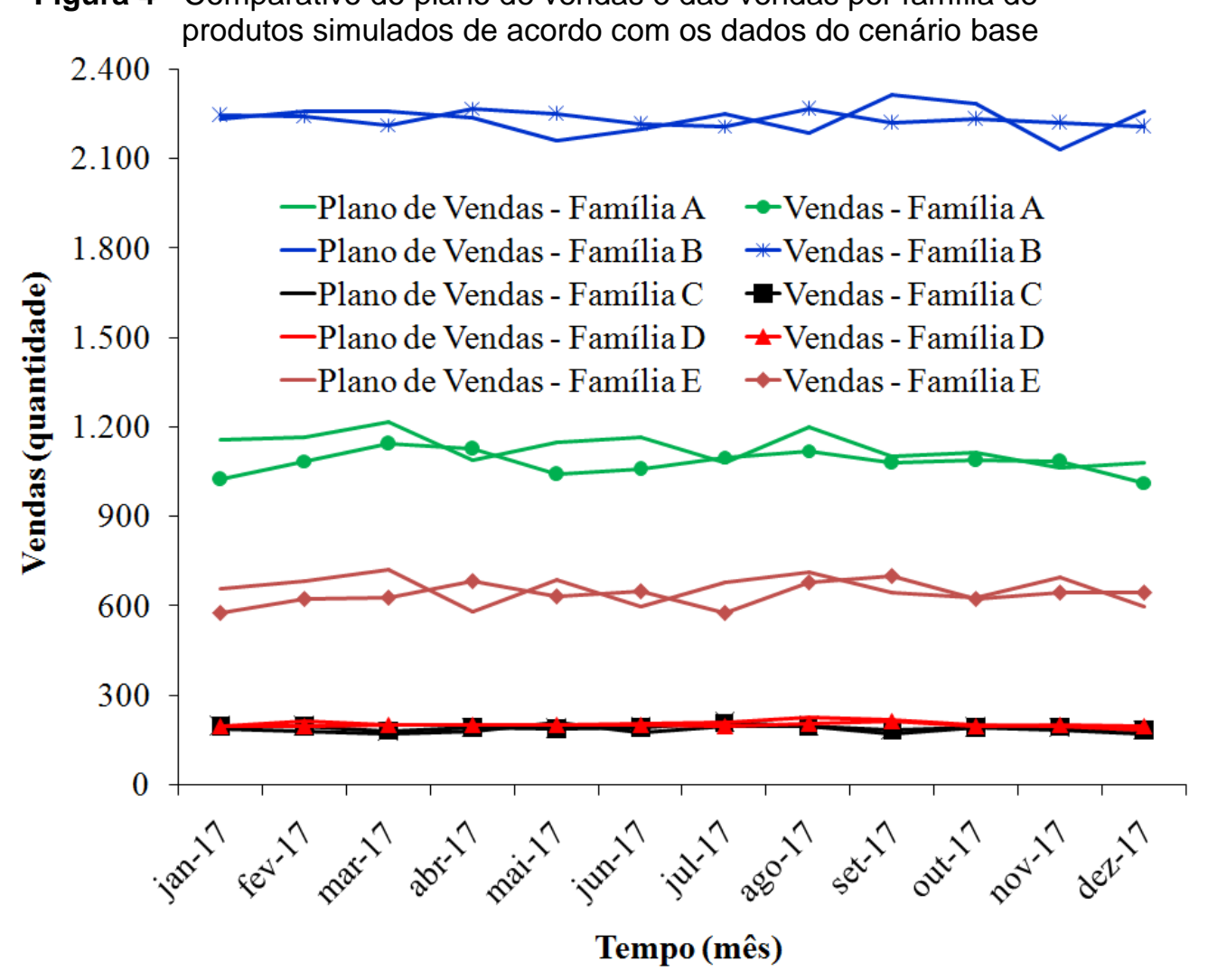

Fonte: Do autor (2017).

Para o cálculo do indicador de desempenho "Percentual de Utilização da Capacidade Restrita", considerou-se a utilização da capacidade do centro 1 , já que este foi definido como o centro restritivo para todas as famílias consideradas no modelo. Desta forma, obteve-se $95,57 \%$ como média mensal do percentual de utilização da capacidade restrita para o centro 1.

De acordo com o percentual obtido, conclui-se que este centro produtivo utilizou sua capacidade quase em sua totalidade, conforme o esperado. Portanto, este centro pode ser considerado um gargalo do sistema produtivo da empresa estudada e deve ser acompanhado com maior atenção pelos gestores para que a produção e, consequentemente, as vendas não sejam prejudicadas devido a uma falha neste centro ou falta de capacidade do mesmo, caso haja um aumento na demanda em determinado período. 
Figura 5 - Totais mensais de demanda, estoque e produção simulados de acordo com os dados do cenário base

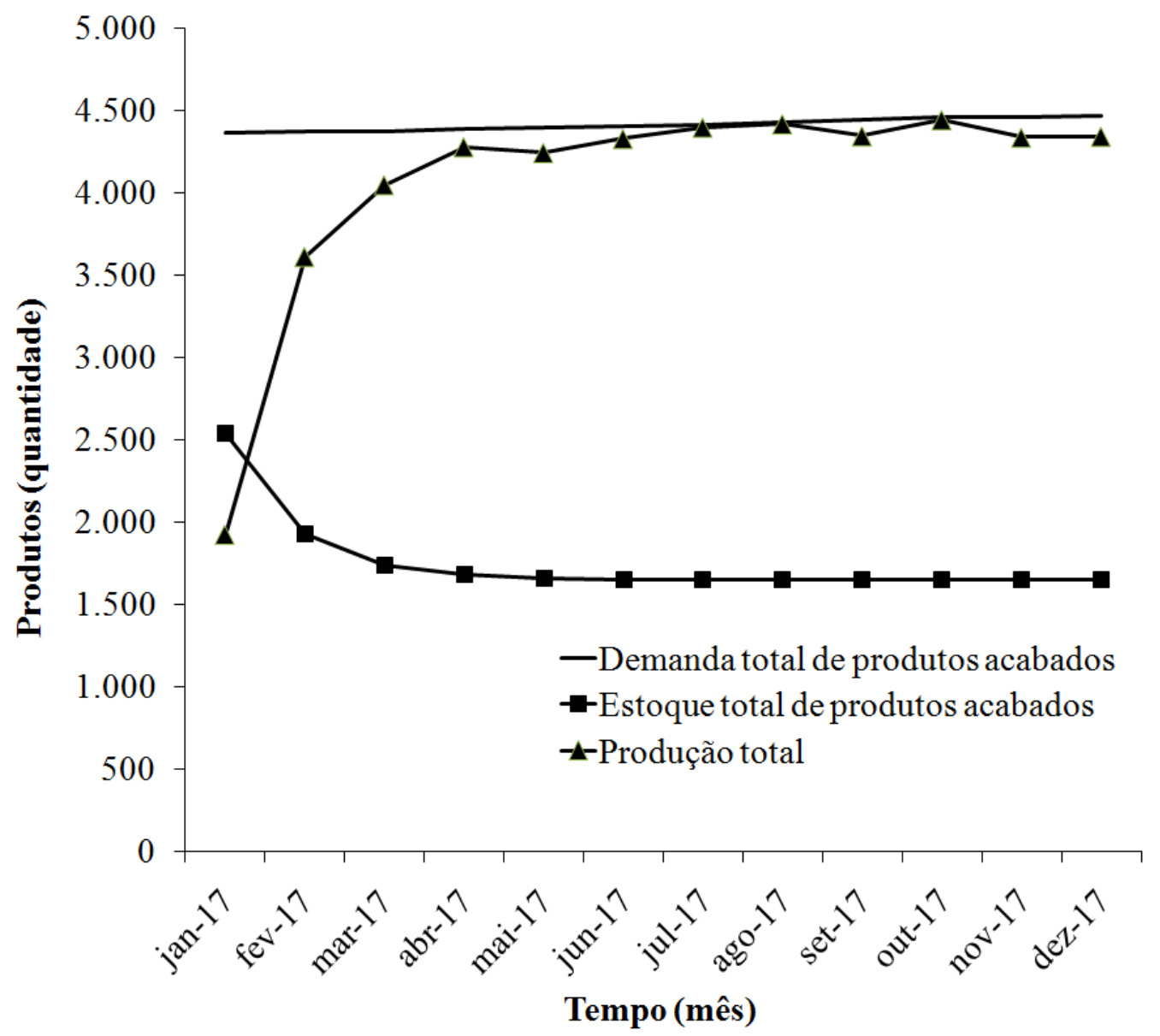

Fonte: Do autor (2017).

\subsection{Análise dos resultados de simulação do cenário 1: influência da redução do estoque desejado no sistema simulado}

Para o cenário 1, definiu-se, para cada família de produto acabado, a redução de $50 \%$ do estoque mensal desejado de produtos, em relação ao estoque mensal desejado do cenário base. Notou-se que o resultado médio obtido para o indicador "Percentual de Atendimento ao Plano de Vendas" total foi de $95,52 \%$ ao mês, ou seja, menor que o percentual apresentado no cenário base. Assim, pode-se observar que, diminuindo-se o nível de cobertura de estoque mensal, pode-se não atender toda a demanda prevista, conforme observa-se na Figura 6. 
Figura 6 - Comparativo do plano de vendas e das vendas por família de produtos acabados simulados de acordo com os dados do cenário 1

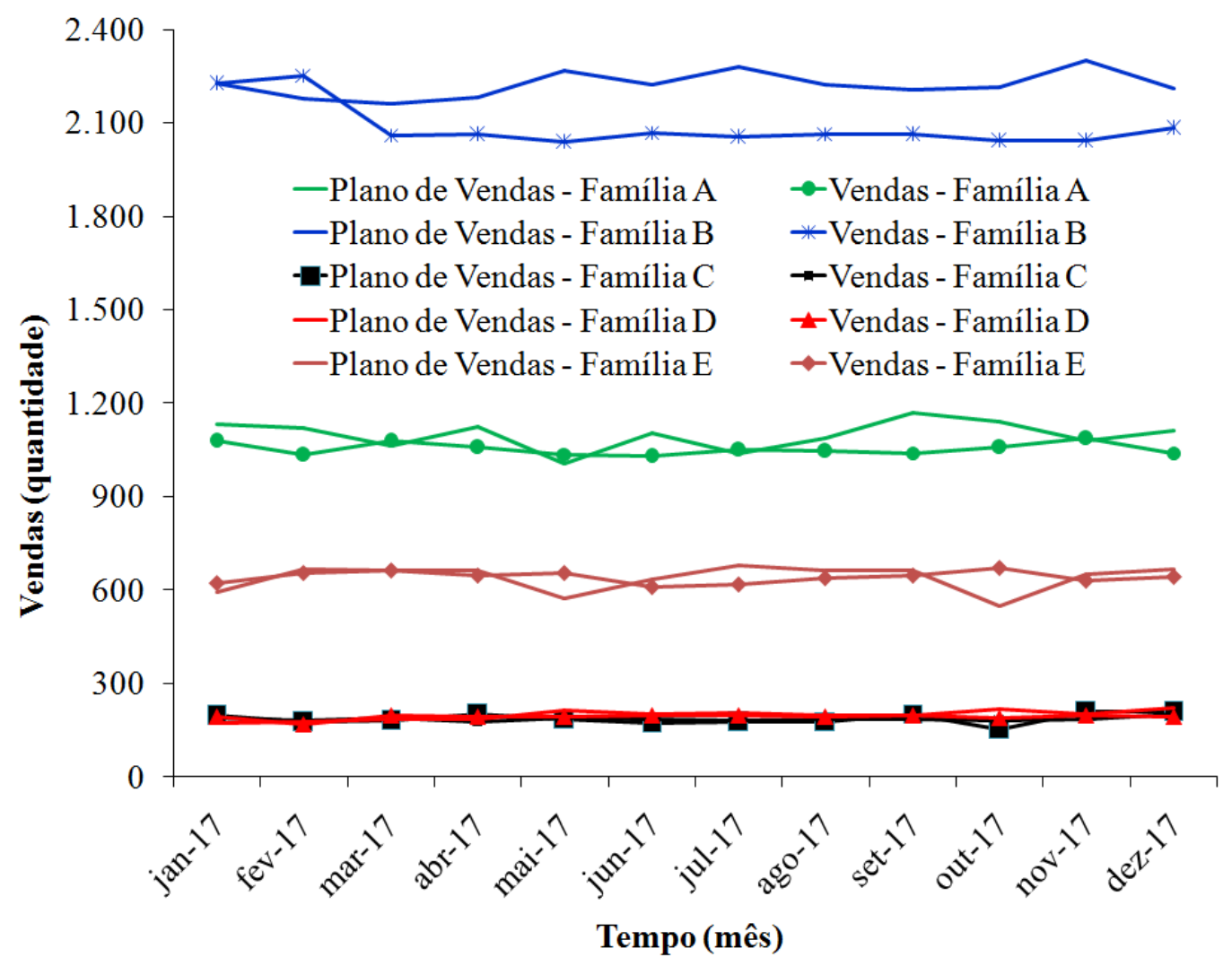

Fonte: Do autor (2017\0.

Em geral, constata-se na Figura 6, portanto, um maior distanciamento entre os planos de vendas e as vendas de cada família de produtos acabados, em alguns meses do período analisado, em comparação ao cenário base. Esta diferença foi mais evidente no caso da família de produtos $B$, pois o percentual de atendimento ao plano de vendas total desta família de produtos atingiu o valor médio de $100 \%$ no cenário base, enquanto que, no cenário 1 , o valor médio obtido foi de $93 \%$. Assim, as vendas totais simuladas no período não atenderam completamente o plano de vendas predito.

Os resultados da simulação também permitiram verificar que, nos meses de setembro e outubro de 2017, a família de produtos A obteve menores percentuais mensais de atendimento ao plano de vendas, em comparação aos do cenário base. No cenário 1 , os percentuais mensais de atendimento ao plano de vendas da família de produtos A foram equivalentes a $89 \%$ para o mês de setembro de 2017 e $93 \%$ 
para o mês de outubro do mesmo ano, enquanto no cenário base estes percentuais foram equivalentes a $98 \%$ para ambos os meses.

Nota-se que, no mês de outubro de 2017, houve um maior distanciamento entre os planos de vendas e as vendas referentes às famílias $C, D$ e $E$ (Figura 6), em comparação ao cenário base (Figura 4).

A produção total obtida no cenário 1 foi equivalente a uma média de 45.944 unidades no ano de 2017. Com base nas informações obtidas, pode-se concluir que, quando se deseja obter um menor nível de produtos acabados em estoque, então, deve-se produzir, proporcionalmente, em menor quantidade visando, assim, um menor acúmulo de estoque. Portanto, a produção deve ser mais sincronizada com a demanda do período.

Observa-se na Figura 7 os totais mensais de demanda, estoque e produção simuladas da empresa estudada no período de 2017 , em função da redução de $50 \%$ do estoque mensal desejado.

Figura 4 - Totais mensais de demanda, estoque e produção simulados no ano de 2017 de acordo com os dados do cenário 1

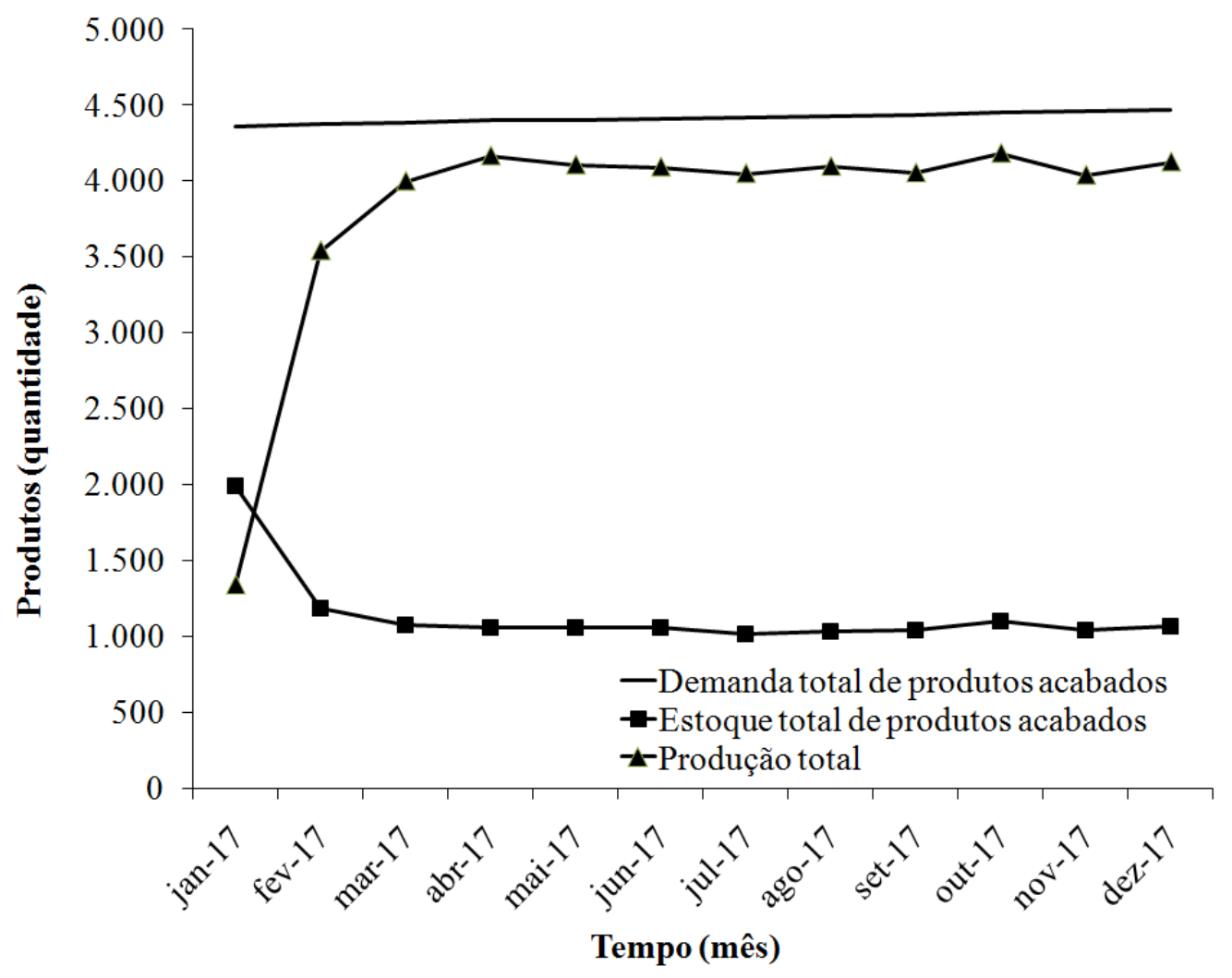

Fonte: Do autor (2017). 
Cabe ressaltar que, na simulação do cenário 1, a demanda permaneceu inalterada. Em contrapartida, a partir da redução do estoque desejado, percebeu-se que, proporcionalmente, a produção diminuiu, em comparação com o cenário base.

De acordo com os resultados, o percentual de utilização da capacidade restrita resultou em uma média de $88,18 \%$ ao mês para o centro restritivo 1 , enquanto que, no cenário base, a utilização do centro 1 foi de $95,57 \%$ ao mês, em média. Percebe-se que, produzindo-se em menor quantidade, os centros de trabalho são menos utilizados e, consequentemente, o percentual de utilização da capacidade restrita é menor.

\subsection{Análise dos resultados de simulação do cenário 2: influência do aumento da previsão de vendas no sistema simulado}

Conforme projeções da ABIGRAF (2016), o segmento da indústria gráfica nacional apresenta perspectiva de crescimento em torno de 4\% para o ano de 2017. Este percentual, entretanto, é maior que o dobro da média mundial do segmento. Assim, para o cenário 2, a previsão de vendas foi aumentada em $4 \%$ ao ano $(0,33 \%$ ao mês) a fim de observar o impacto desta projeção otimista no sistema produtivo da empresa pesquisada.

Conforme constata-se na Figura 8, as vendas se aproximaram do plano de vendas para todas as famílias de produtos acabados, indicando um adequado atendimento ao plano de vendas.

De acordo com os resultados da simulação, o percentual médio de atendimento ao plano de vendas foi de $99,35 \%$ ao mês, ou seja, maior que o do cenário base. Portanto, pode-se concluir que, com o aumento da previsão de vendas para o ano de 2017, para a empresa atender a nova demanda de forma satisfatória, é necessário adequar sua capacidade produtiva, conforme previsto pelo modelo simulado e constatado pelo indicador "percentual de utilização da capacidade restrita", discutido adiante.

Um aumento nas variáveis "previsão de vendas" e "demanda" em $4 \%$ ao ano influenciou, como esperado, a produção total que aumentou em relação ao cenário base, atingindo o valor de 65.460 unidades produzidas no ano de 2017. 
Figura 8 - Comparativo do plano de vendas e das vendas por família de produtos acabados simulados de acordo com os dados do cenário 2

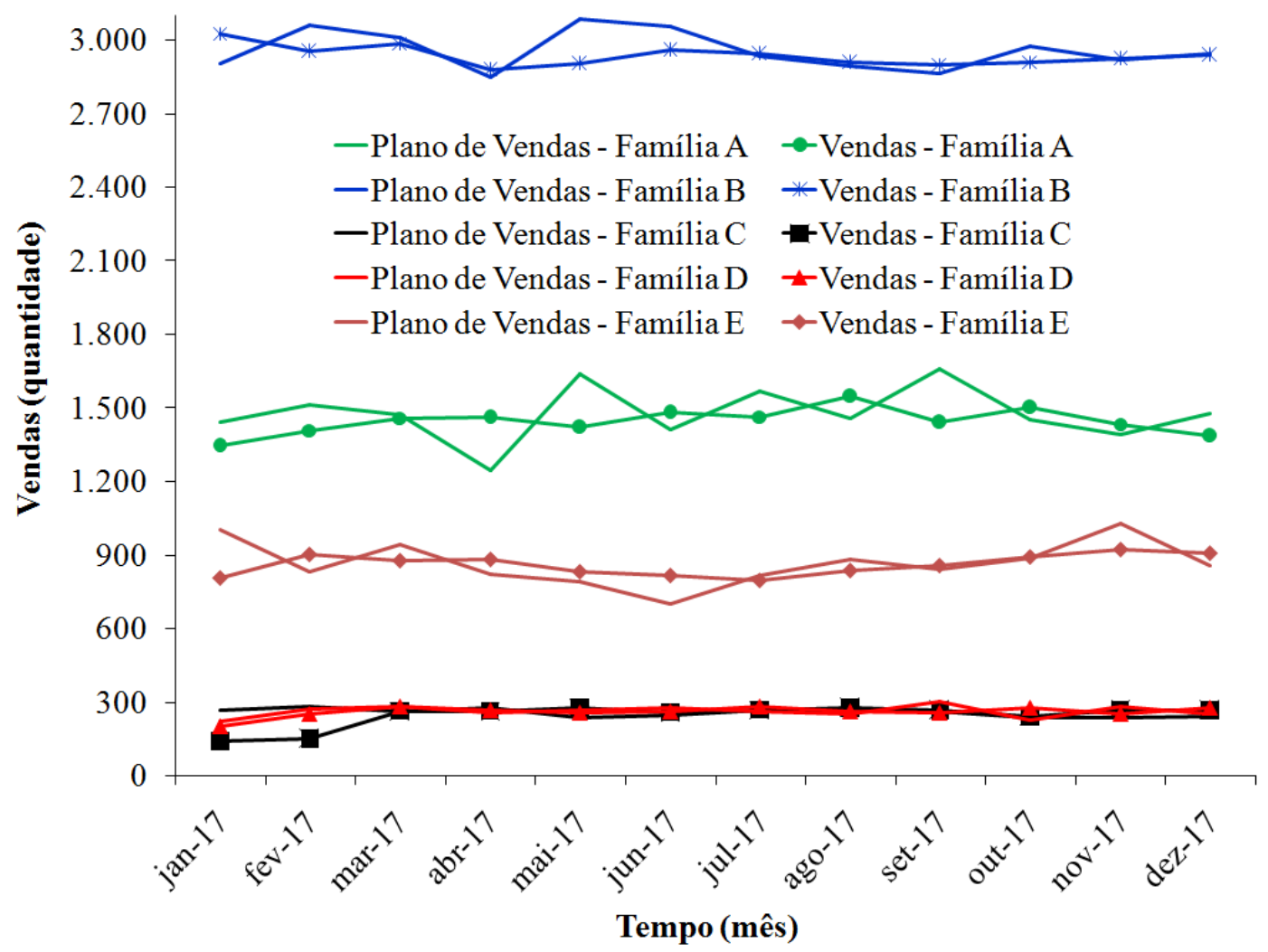

Fonte: Do autor (2017).

Na Figura 9 notam-se os totais mensais de demanda, estoque e produção simulados, de acordo com os dados do cenário 2.

Verificou-se que, em todos os meses de 2017, houve um considerável aumento do volume de produção em relação aos outros cenários, em consequência do aumento da demanda prevista. Observou-se que, ao longo do ano em questão, o volume mensal de produção foi maior que a demanda, à exceção dos meses de janeiro e dezembro cujos volumes de produção foram menores que as demandas. Em janeiro de 2017, constatou-se que a produção total foi menor que a demanda devido a um maior nível de estoque. O volume de produção ao fim do período simulado, mês de dezembro, também foi menor que a demanda do mês devido ao acúmulo de estoque gerado pelo sistema produtivo durante os meses anteriores. Este acúmulo de estoque, juntamente com a produção, atendeu, satisfatoriamente, à demanda. 
Figura 9 - Totais mensais de demanda, estoque e produção simulados de acordo com os dados do cenário 2

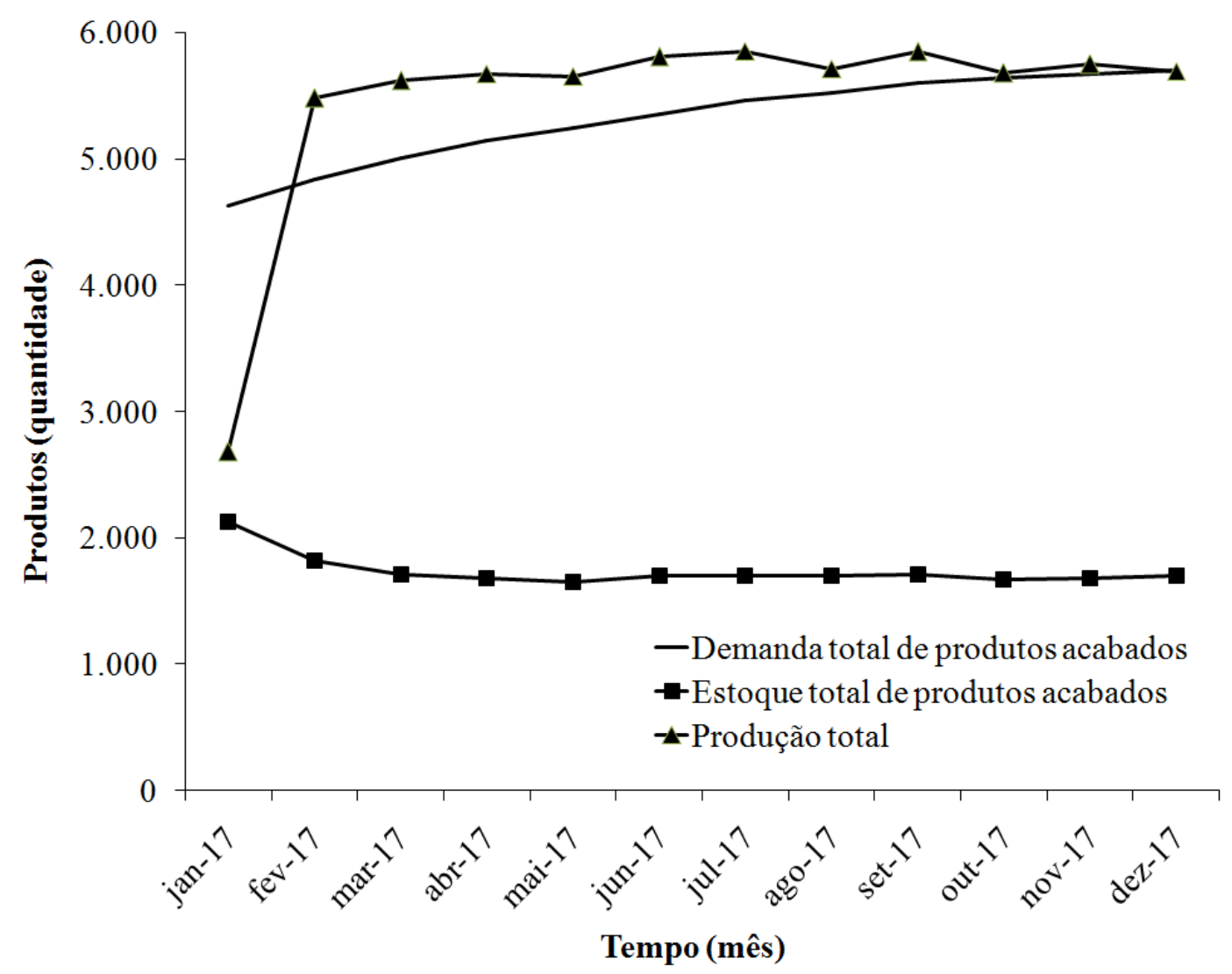

Fonte: Do autor (2017).

Em razão do volume de produção ter sido maior que a demanda para os meses de fevereiro a novembro de 2017, pode-se concluir que o acúmulo de estoques de produtos acabados foi relevante para o atendimento à demanda que, por sua vez, apresentou tendência de crescimento para este ano.

Devido ao aumento da demanda e, consequentemente, ao aumento da produção, os centros de trabalho foram utilizados além de suas capacidades. Para o centro restrito 1, o percentual de utilização da capacidade restrita médio gerado por meio da simulação foi de $124,77 \%$ ao mês. Dessa maneira, constatou-se a necessidade de adoção de horas extras e/ou alocação de mais maquinário para atendimento aos planos de vendas, estoque e de produção. Cabe ressaltar que, no cenário base e no cenário 1 , não houve necessidade de horas extras e/ou alocação de mais maquinário.

Notou-se, ainda, que, além do centro 1 , todos os demais centros de trabalho utilizaram mais de $100 \%$ de suas respectivas capacidades disponíveis. Ou seja, em 
todos os centros foi necessário um incremento da capacidade por meio da adoção de horas extras ou da alocação de mais maquinário, ou por meio de ambas as ações, impactando em maiores custos para a empresa estudada. Portanto, um incremento da capacidade deve ser avaliado de maneira criteriosa pelos gestores neste cenário.

\subsection{Análise dos resultados de simulação do cenário 3: influência da redução do estoque desejado e do aumento da previsão de vendas no sistema simulado}

No cenário 3, diminuindo-se em 50\% o estoque mensal desejado e aumentando-se a previsão de vendas em 0,33\% ao mês, obteve-se o menor valor para o indicador "Percentual de Atendimento ao Plano de Vendas", quando comparado ao cenário base e aos cenários 1 e 2 . O resultado médio deste indicador foi equivalente a $91,84 \%$ ao mês. Assim, pode-se concluir que a baixa cobertura de estoque, em conjunto com o aumento das vendas, contribuiu para que a demanda não fosse atendida em sua totalidade.

De acordo com os resultados apresentados na Figura 10, percebe-se que 0 percentual de atendimento ao plano de vendas que sofreu maior impacto foi 0 referente à família $B$, em comparação com as demais famílias de produtos acabados. A família B envolve os itens de maior demanda, sendo previsível, portanto, um baixo percentual de atendimento ao plano de vendas relacionado a esta família, uma vez que a demanda prevista foi aumentada, mas o estoque desejado foi reduzido.

No cenário 3, uma vez que a cobertura de estoque mensal de produtos acabados foi baixa e a demanda foi alta, a produção, nesse caso, aumentou de forma considerável conforme pode ser visto na Figura 11. A média de produção foi de 60.359 unidades no ano de 2017, o que foi consideravelmente maior que a produção do cenário base. 
Figura 10- Comparativo do plano de vendas e das vendas por família de produtos acabados simulados de acordo com os dados do cenário 3

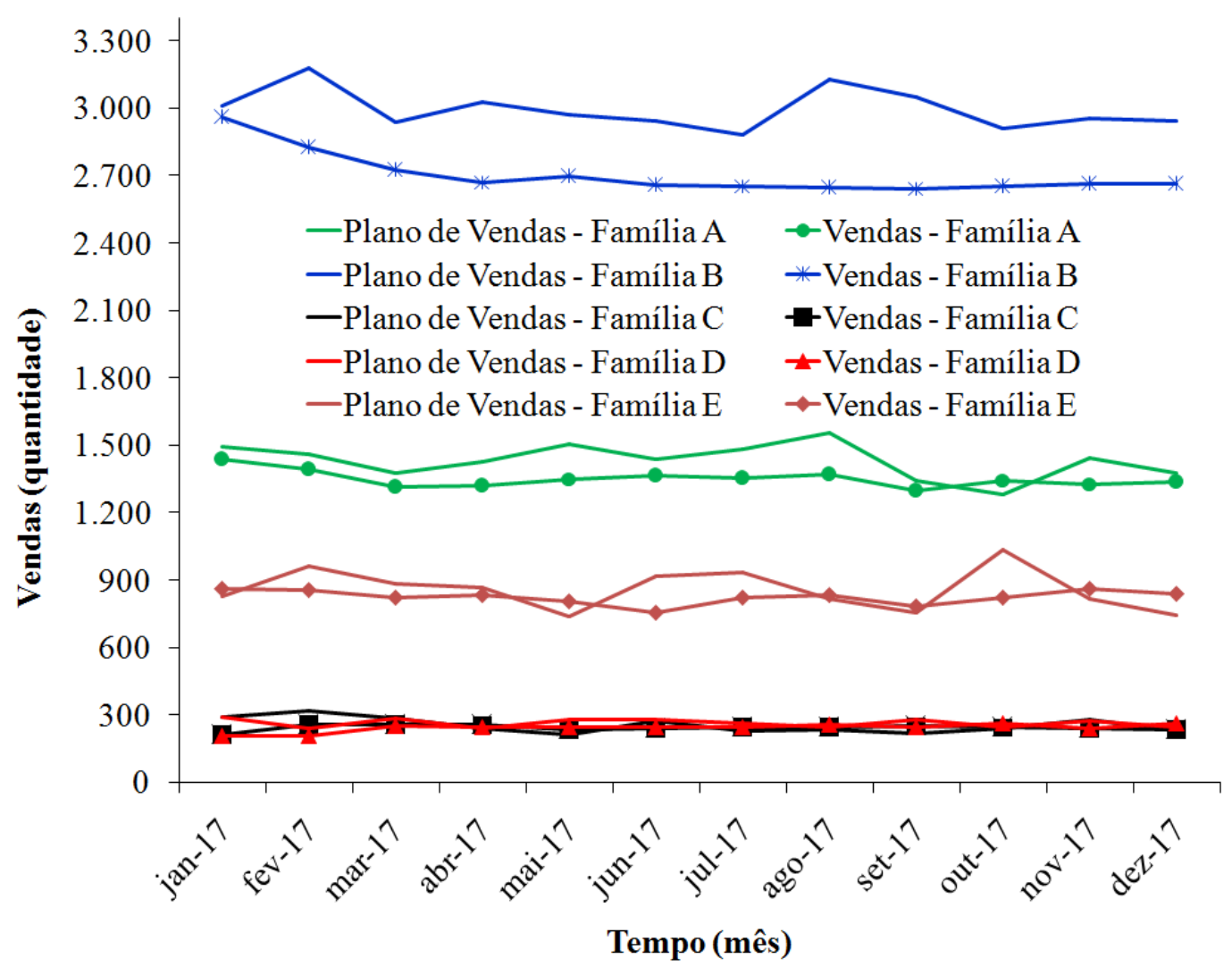

Fonte: Do autor (2017).

Pode-se concluir que, quando há um baixo nível de estoque mensal de produtos acabados e, simultaneamente, um aumento da demanda mensal, a produção deve ser aumentada para suprir as necessidades da empresa e atender as metas propostas nos planos mensais de venda, estoque e produção. De acordo com a Figura 11, nota-se um elevado nível de produção em todos os meses do ano de 2017. O nível de estoque também se apresentou elevado a fim de atender a demanda, que, por sua vez, se comportou de maneira crescente no período analisado. Elevados níveis de produção e de estoque foram constatados, especialmente nos 5 primeiros meses do ano. Inclusive, para os meses de fevereiro, março e abril, o volume de produção foi maior que a demanda para estes mesmos meses.

À exceção do mês de janeiro de 2017, verificou-se que os níveis de produção e estoque referentes aos demais meses do ano foram, consideravelmente, estáveis mesmo com o aumento da demanda prevista e redução do estoque para o período. 
Este fato comprova que o ciclo de retroalimentação (feedback) de equilíbrio considerado nesta parte do modelo simulado predomina em relação ao ciclo de reforço.

Figura 11 - Totais mensais de demanda, estoque e produção simulados no período de 2017 de acordo com os dados do cenário 3

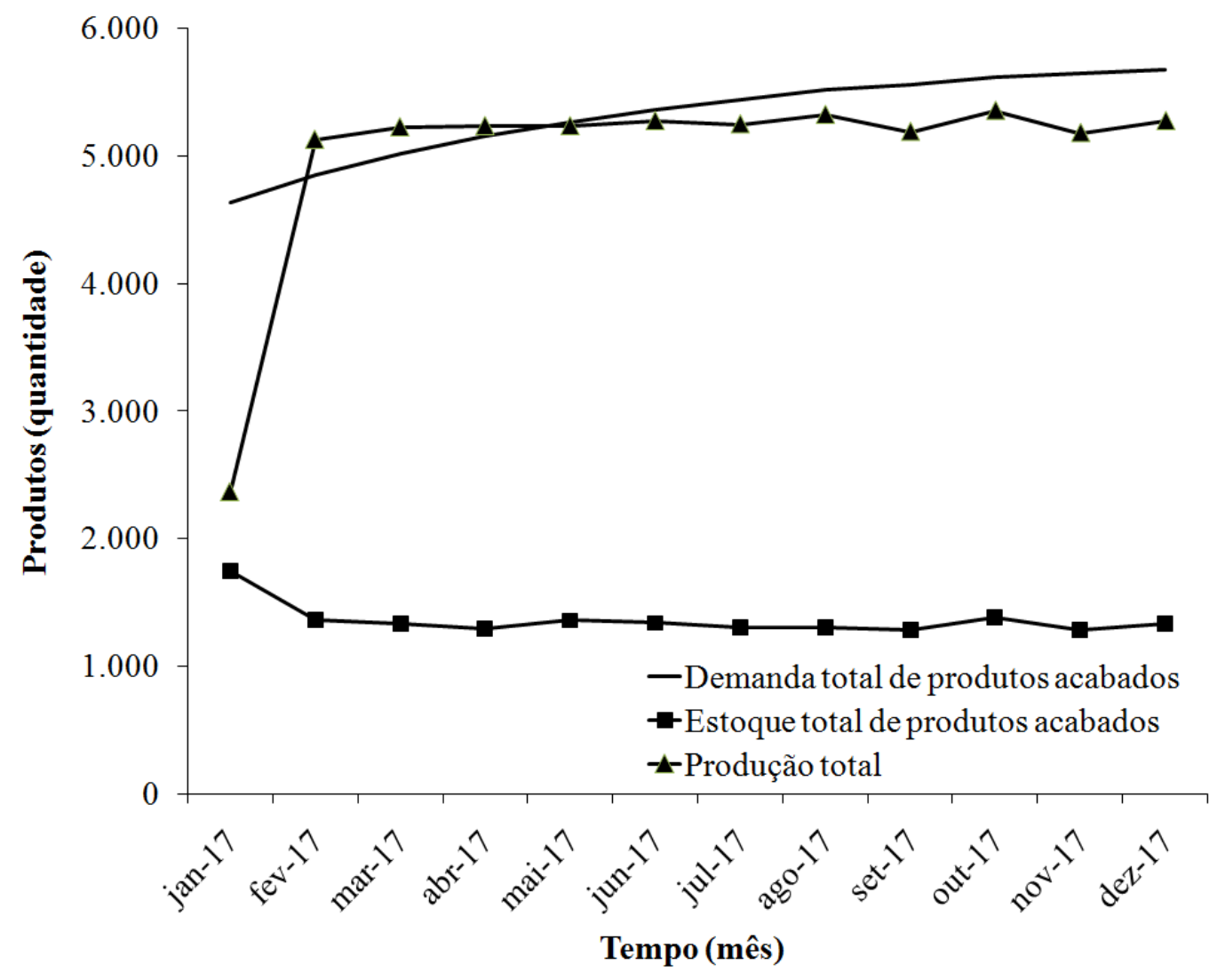

Fonte: Do autor (2017).

Verificou-se ainda que a média do percentual de utilização da capacidade restrita aumentou em relação ao cenário base passando a ser igual a $115,58 \%$ ao mês. Assim, para o cenário 3, este percentual obtido demonstrou a necessidade de um incremento da capacidade em função da redução do nível de estoque e do aumento da previsão de vendas, por meio da adoção de horas extras e/ou alocação de mais maquinário para o atendimento à demanda prevista. Esse fato implica em maiores custos para as empresas e deve ser avaliado criteriosamente pelos gestores. 


\subsection{Comparação entre os indicadores de desempenho dos cenários simulados}

$\mathrm{Na}$ Tabela 2 apresenta-se um comparativo entre os resultados dos indicadores de desempenho anuais de cada cenário, obtidos por meio das simulações para o período analisado.

Tabela 2 - Resultados dos indicadores de desempenho anuais de cada cenário obtidos por meio das simulações

\begin{tabular}{cccc}
\hline Cenário & $\begin{array}{c}\text { \% Atend. ao } \\
\text { plano de vendas }\end{array}$ & $\begin{array}{c}\text { Produção } \\
\text { total }\end{array}$ & $\begin{array}{c}\text { \% Utiliz. } \\
\text { capacidade restrita }\end{array}$ \\
\hline Base & 98,31 & 47563 & 95,57 \\
1 & 95,52 & 45944 & 88,18 \\
2 & 99,35 & 65460 & 124,77 \\
3 & 91,84 & 60359 & 115,58 \\
\hline
\end{tabular}

Fonte: Do autor (2017).

De acordo com a Tabela 2, pode-se constatar que, no cenário 1, ao reduzir em $50 \%$ o percentual de estoque desejado de produtos acabados em relação ao cenário base, houve um impacto pequeno na produção total gerando uma redução de apenas 3,4\%. Essa redução na produção, consequentemente, gerou uma redução no percentual de utilização da capacidade do centro restrito de $7,4 \%$. Entretanto, mesmo considerando essas reduções, não houve um grande comprometimento nas vendas totais já que, comparado ao cenário base, houve uma redução de apenas 2,8\% no percentual de atendimento ao plano de vendas. Dessa maneira, conclui-se, por meio dos resultados do cenário 1, que a empresa analisada poderia reduzir seu estoque desejado reduzindo, assim, seus custos sem comprometer significativamente suas vendas.

$\mathrm{Na}$ Tabela 2, constata-se ainda que, com o aumento de 0,33\% da previsão mensal de vendas no cenário 2 (aumento de 4\% ao ano), houve um aumento de 27,3\% na produção total anual da empresa, comparada à produção do cenário base. Este cenário foi o que obteve maior percentual de atendimento ao plano de vendas dentre os demais cenários indicando que a previsão de vendas da empresa foi realizada de maneira mais assertiva. Em contrapartida, o percentual de utilização da capacidade restrita foi de $124,77 \%$, ou seja, ultrapassou $100 \%$, o que indica a necessidade de contratação de horas extras e/ou alocação maior de maquinário. Este fato, se por um lado é satisfatório, já que se utilizou ao máximo a capacidade 
do centro de trabalho restrito 1 , considerado o gargalo produtivo da empresa analisada, por outro lado impacta os custos da empresa. Portanto, se realmente houver um aumento da demanda, os gestores devem analisar com maior rigor os recursos necessários para o financiamento do capital de giro adicional requerido, pois, caso contrário, a empresa poderá vivenciar uma situação de overtrading. De acordo com Marques (1995), overtrading é o desequilíbrio econômico financeiro que ocorre quando o capital de giro da empresa se revela insuficiente para suprir o seu nível de atividade, podendo ocasionar a falência da empresa.

Ao analisar os resultados do cenário 3 e compará-los aos resultados dos demais cenários, pode-se afirmar que a redução de estoque desejado em conjunto com o aumento da previsão de vendas gerou maior impacto nas vendas, já que o percentual de atendimento ao plano de vendas foi o menor dentre todos os cenários e, em relação ao cenário base, foi menor em torno de $6,5 \%$. Por meio do percentual de utilização da capacidade restrita, pode-se constatar também que, assim como no cenário 2, houve uma utilização do centro restrito 1 acima da sua capacidade atualmente disponível indicando também a necessidade de expansão da capacidade produtiva da empresa.

\section{CONCLUSÃO}

Neste trabalho, analisou-se a gestão da produção em uma empresa de pequeno porte que fabrica produtos ligados à comunicação visual, utilizando-se a técnica de dinâmica de sistemas. Com o objetivo de avaliar o desempenho atual da empresa e melhor compreender os fatores que afetam diretamente o seu desempenho produtivo foram simulados quatro cenários.

Os resultados das simulações e análises dos cenários propostos permitem concluir que a análise da gestão da produção da empresa estudada utilizando-se a técnica de DS é viável e relevante para auxiliar os gestores na tomada de decisão quanto à definição dos planos de vendas, estoque e produção e à identificação do impacto dos gargalos produtivos no sistema.

Quanto ao desempenho atual da empresa pesquisada, concluiu-se que o atual sistema de fabricação de produtos padronizados da empresa atende, de forma 
satisfatória, a demanda atual do mercado, de acordo com o valor médio de 98,3\% ao mês do "percentual de atendimento ao plano de vendas" obtido na simulação do cenário base. Adicionalmente, o resultado médio do "percentual de utilização da capacidade restrita" demonstra que a capacidade utilizada do centro restritivo 1 é superior a 95\% de sua capacidade atual disponível. Este percentual comprova que, no cenário atual, os gestores da empresa conseguem alocar adequadamente a mão de obra e demais recursos produtivos programando a produção próxima da máxima capacidade do gargalo de seu processo produtivo.

A partir dos resultados do cenário 1, comprovou-se que a empresa pode reduzir seu estoque desejado reduzindo, assim, seus custos, sem comprometer significativamente o atendimento ao plano de vendas.

De acordo com a simulação do cenário 2, constatou-se que um aumento na previsão de vendas anual da empresa (4\% a.a.) gera um grande impacto na produção total, aumento de 27,3\%, e na utilização do centro restrito 1, gargalo do processo produtivo da empresa, que ultrapassou em torno de $25 \%$ sua capacidade máxima disponível. Este fato chama atenção já que, se realmente houver um crescimento do mercado nacional do setor gráfico, a empresa analisada talvez não consiga atender essa nova demanda e, portanto, deve analisar com maior rigor os recursos necessários para o financiamento do capital de giro adicional requerido, a fim de evitar o overtrading.

Por fim, conclui-se que a implementação do modelo de DS na indústria gráfica trouxe não apenas ganhos acadêmicos, mas também organizacionais comprovando sua eficácia na prática. Destaca-se que o modelo apresentado serve de referência para análise de sistemas produtivos de qualquer tipo de indústria com produção discreta e sistema MTS, independente de ser do setor gráfico.

Sugere-se, para trabalhos futuros, implementar e simular, utilizando os dados reais da empresa estudada, o modelo integrado à área financeira a fim de proporcionar aos gestores uma visão ainda mais holística do sistema da empresa em questão e adaptar o modelo para se adequar também ao sistema produtivo make-to-order (MTO). 


\section{REFERÊNCIAS}

ABIGRAF - Associação Brasileira da Indústria Gráfica. Análises. São Paulo: ABIGRAF, 2016.

DE MEDEIROS JÚNIOR, Josué Vitor et al. Visão baseada em recursos dinâmicos: estudo das contribuições da área de Dinâmica de Sistemas (DS) para a Teoria da Visão Baseada em Recursos (VBR). Revista Ibero Americana de Estratégia, v. 8, n. 1, 2009.

https://doi.org/10.5585/riae.v8i1.1628

DOMINGOS, Jean Carlos; POLITANO, Paulo Rogério; PEREIRA, Néocles Alves. Modelo de dinâmica de sistemas para o processo de S\&OP ampliado. Gestión y producción, p. 755788, 2015. https://doi.org/10.1590/0104-530X1702-14

FORRESTER, Jay W. Industrial dynamics—after the first decade. Management Science, v. 14 , n. 7 , p. 398-415, 1968. https://doi.org/10.1287/mnsc.14.7.398

GODINHO FILHO, Moacir; UZSOY, Reha. Efeito da redução do tamanho de lote e de programas de Melhoria contínua no estoque em processo (WIP) e na utilização: estudo utilizando uma abordagem híbrida System Dynamics-FactoryPhysics. Production, v. 19, n. 1, p. 214-229, 2009. ISSN 1980-541. Disponível em:

https://www.redalyc.org/pdf/3967/396742035013.pdf. Acesso em: 10 set. 2016.

http://dx.doi.org/10.1590/S0103-65132009000100014

HSIEH, Yen-Hao; CHOU, Yun-Hsuan. Modeling the impact of service innovation for small and medium enterprises: A system dynamics approach. Simulation Modelling Practice and Theory, v. 82, p. 84-102, 2018. https://doi.org/10.1016/j.simpat.2017.12.004

KRALIK, Letícia Schumacher; FOGLIATTO, Flávio Sanson. Método para implementação de planejamento de vendas e operações (S\&OP) aplicado em empresa do ramo automotivo.

Revista Produção Online, v. 16, n. 3, p. 781-800, 2016. https://doi.org/10.14488/16761901.v16i3.1992

LEITE, Caio Cesar Lemes et al. A LOGÍSTICA E A GESTÃO DA CADEIA DE

SUPRIMENTOS: um estudo de caso em uma empresa da região do sul de Minas Gerais.

Revista da Universidade Vale do Rio Verde, v. 15, n. 1, p. 676-688, 2017. Disponível em: http://periodicos.unincor.br/index.php/revistaunincor/article/view/4046/3014. Acesso em: 02 out. 2017. http://dx.doi.org/10.5892/ruvrd.v15i1.4046

MARQUES, José Augusto Veiga da Costa; BRAGA, Roberto. Análise dinâmica do capital de giro: o modelo Fleuriet. Revista de Administração de Empresas, v. 35, n. 3, p. 49-63, 1995. https://doi.org/10.1590/S0034-75901995000300007

MORAIS, Roberto Ramos de. Modelagem para estudo do comportamento dos elos da cadeia de suprimentos. 2004. Tese (Doutorado) - Universidade de São Paulo, 2004. http://dx.doi.org/10.11606/D.3.2004.tde-30082005-102549

NASCIMENTO, Bruno Oliveira. Análise e simulação da gestão da produção de empresa com foco em fabricação para estoque: uma abordagem de dinâmica de sistemas. 2017. Dissertação (Mestrado) - Faculdade letec, 2017. 
PEDROSO, Carolina Belotti; SILVA, A. L. Dinâmica de implantação do Sales and Operations Planning: principais desafios. Gestão \& Produção, v. 22, n. 3, p. 662-677, 2015. Disponível em: http://www.scielo.br/pdf/gp/2015nahead/0104-530X-gp-0104-530X1754-14.pdf. Acesso em: 21 fev.2 017. https://doi.org/10.1590/0104-530X1754-14

RICHMOND, Barry. Systems thinking: critical thinking skills for the 1990s and beyond. System dynamics review, v. 9, n. 2, p. 113-133, 1993.

https://doi.org/10.1002/sdr.4260090203

SENGE, Peter. The Fifth Discipline: the art and practice of the learning organization.

Random House, 1994.

SOUZA, Fernando Bernardi De; PIRES, Silvio Roberto Ignácio. Produzindo para disponibilidade: uma aplicação da Teoria das Restrições em ambientes de produção para estoque. Gestão \& Produção, p. 65-76, 2014. Disponível em:

http://www.scielo.br/pdf/gp/v21n1/aop a1204.pdf. Acesso em: 12 jan. 2017. https://doi.org/10.1590/S0104-530X2013005000007

STERMAN, J. D. Business dynamics: systems thinking and modeling for a complex world. Boston: McGraw Hill Higher Education, 2000.

SURYANI, Erma et al. Demand scenario analysis and planned capacity expansion: A system dynamics framework. Simulation Modelling Practice and Theory, v. 18, n. 6, p. 732-751, 2010. Acesso em: 2 ago.2016. https://doi.org/10.1016/i.simpat.2010.01.013

TOMAS, Robson Nogueira; SATO, Levi; ALCANTARA, Rosane Lucia Chicarelli. Planejamento de vendas e operações (S\&OP) no segmento de bens de consumo: uma análise envolvendo o estágio de maturidade do processo. Revista de Administração, v. 10, n. 3, p. 1-25, 2012. Disponível em:

http://www.raunimep.com.br/ojs/index.php/regen/article/view/428. Acesso em: 26 fev. 2017.

ZATTAR, Izabel Cristina; MATHEUS, Caroline Kiume. Desenvolvimento de ferramenta de análise S\&OP em uma empresa de telecomunicações: um estudo de caso aplicado.

Iberoamerican Journal of Industrial Engineering, v. 8, n. 15, p. 90-113, 2016.

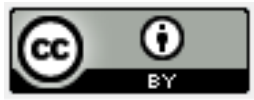

Artigo recebido 05/05/2019 e aceito para publicação em: 07/06/2020

DOI: http://dx.doi.org/10.14488/1676-1901.v20i2.3642 